\title{
Gas chromatographic enantioseparation of fluorinated anesthetics: Single column performance and scale-up estimation
}

\author{
Ivana Mutavdžin ${ }^{1 *}$, Thomas Munkelt ${ }^{2}$, Dirk Enke ${ }^{3}$, Andreas Seidel-Morgenstern ${ }^{1,2}$ \\ ${ }^{1}$ Max Planck Institute for Dynamics of Complex Technical Systems, Sandtorstraße 1, 39106 Magdeburg, \\ Germany \\ ${ }^{2}$ Otto von Guericke University, Institute of Process Engineering, Universitätsplatz 2, 39106 Magdeburg, \\ Germany \\ ${ }^{3}$ Universität Leipzig, Institute of Chemical Technology, Linnestraße 3, 04103 Leipzig, Germany \\ *Correspondence: Ivana Mutavdžin (E-mail: mutavdzin@mpi-magdeburg.mpg.de), Max Planck Institute for \\ Dynamics of Complex Technical Systems, Sandtorstraße 1, 39106 Magdeburg, Germany
}

\section{Abstract}

The paper presents results of a study devoted to provide the pure enantiomers of isoflurane and desflurane from racemic mixtures using gas chromatography. For that purpose a cyclodextrin based selector described in earlier work was immobilized on porous glass beads. The adsorption isotherms were determined and applied to predict operating parameters which provide the highest possible productivity of the separation. The analysis included evaluation of the performance of larger columns applying simplifying scale-up considerations. Using repetitive batches the method can provide per day with a laboratory scale column $(40 \times 1.56 \mathrm{~cm})$ approximately 1 gram pure enantiomer. Selected model predictions were validated experimentally. Keywords: Enantiomers, Isoflurane and desflurane, Productivity, Scale-up, Diluted gaseous systems

\section{Introduction}

The separation of enantiomers is of large relevance in the pharmaceutical industry. Although enantiomers have the same physico-chemical properties, in living organisms they have very often different effects. Still a large number of drugs are used as racemic mixtures, containing both enantiomers in equal amounts. For this reason it is important to develop enantioseparation processes. Preparative chromatography is known to be one of the most suitable techniques available.

The main objective of our work was to design a process for producing pure enantiomers of two fluorinated anesthetic gases: isoflurane and desflurane. Nowadays they are applied in racemic form, although the mechanism of action of single enantiomers is not completely known. There is a possibility to improve the anesthesia by using only the enantiomer with more favorable properties. Another reason to get pure enantiomers is to use them to examine the mechanism of anesthesia [1].

Received: June 08, 2018; revised: August 22, 2018; accepted: October 31, 2018

This article has been accepted for publication and undergone full peer review but has not been through the copyediting, typesetting, pagination and proofreading process, which may lead to differences between this version and the final Version of Record (VOR). This work is currently citable by using the Digital Object Identifier (DOI) given below. The final VoR will be published online in Early View as soon as possible and may be different to this Accepted Article as a result of editing. Readers should obtain the final VoR from the journal website shown below when it is published to ensure accuracy of information. The authors are responsible for the content of this Accepted Article.

To be cited as: Chem. Eng. Technol. 10.1002/ceat.201800294

Link to final VoR: https://doi.org/10.1002/ceat.201800294

This article is protected by copyright. All rights reserved. 
This work describes results of investigating enantioselective gas chromatography (GC), comprising experimental and simulation studies. The experimental part included investigation of the suitable adsorbents and columns, synthesis of the chiral selector, development of the new stationary phase and GC injections. It served to validate the predictions and to produce pure enantiomers. The main task of the simulation study was to provide the understanding and planning of the separation process. It included analysis of the process model, estimation of the adsorption isotherms and other parameters and simulation of the process in order to improve it and maximize the production. Isotherm estimation and column characterization represented a challenging task since there were no single enantiomers available to carry out preliminary experiments.

Apart from producing pure enantiomers, one of the ideas of this work was to investigate the procedure for simple and fast analysis of a GC process when the studied systems are diluted. While liquid chromatography models have been widely analyzed, gaseous systems are still not present in the research at such large extent. In general, description of the processes occurring in the gas phase requires larger number of parameters than liquid systems and therefore more experimental and computational work. In this study a simplified model was used and validated experimentally.

\section{Chiral compounds and chromatographic system investigated}

This study dealed with two fluorinated volatile anesthetics: isoflurane (2-chloro-2-(difluoromethoxy)1,1,1-trifluoroethane) and desflurane (2-(difluoromethoxy)-1,1,1,2-tetrafluoroethane). The enantiomers of both compounds have the same absolute configurations [2, 3], namely (+)-Senantiomer and (-)-R-enantiomer.

Differences in action of single enantiomers of the fluorinated anesthetics were examined in many studies. Research conducted on animals [4-10] and humans [11-13] has showed that S-enantiomer of both isoflurane and desflurane is more effective as an anesthetic and is faster eliminated from the body. Yet, more tests with pure substances should be done to clarify the action of the enantiomers.

Although the synthesis of isoflurane and desflurane enantiomers was reported $[10,14,15]$, the easiest way to obtain them is by racemate separation. A comprehensive report on enantioseparation of fluorinated anesthetics was provided by V. Schurig [16]. Taking into account their low boiling points, GC has been identified as the most suitable separation technique. By introducing stationary phases based on $\alpha$-, $\beta$ - and $\gamma$-cyclodextrins (CDs) for separation of enantiomers [17] and providing their derivatives for separating racemic mixtures of fluorinated anesthetics [18-20], their enantioseparation became possible.

The first chiral separation of the mentioned anesthetics was performed on a microscale level [21] using derivatives of $\alpha$ - and $\gamma$-CD. The $\gamma$-CD derivative Octakis(3-O-butyryl-2,6-di-O-pentyl)- $\gamma$ cyclodextrin developed by König et al. [22] provided further successful separations of racemic mixtures of the anesthetics in (semi)preparative single columns $[19,23,24]$ and by simulated moving bed (SMB) for isoflurane [25]. The stationary phase was prepared by dissolving the selector ( $\gamma$-CD derivative) in polysiloxane SE-54 and then coating it onto Chromosorb particles. A new support for 
immobilizing the selector made of porous glass beads has been recently introduced [26]. Further experimental tests on SMB and theoretical studies were reported only for enflurane (not studied here) [27-31].

Based on the pioneer works $[19,23,24]$ we studied the enantioseparation of isoflurane and desflurane using $\gamma$-CD derivative established in [22] dissolved in polysiloxane SE-54 and coated onto the newly developed porous glass beads similar to those in [26].

\section{Theory and procedures}

The applied concept for process development and analysis consisted of three parts: a) Characterization of the thermodynamics by analyzing experimental chromatograms of injections of racemic-mixtures, b) Model-based simulation studies of process performance and c) Experimental validation of the applicability of a simple scale-up rule.

\subsection{Determination of adsorption isotherms using the peak-fitting method}

Development of a chromatographic process requires knowledge of adsorption isotherms. From different methods for measuring the isotherm parameters $[32,33]$ several could be applied for racemates [34-37]. Since our columns had low efficiency and there was no access to pure enantiomers, the only applicable method was the peak-fitting (inverse) method. It was probably first applied in [38] for one component isotherm and then further elaborated for determination of competitive isotherms [36, 39-41]. It does not require highly efficient columns, since the dispersion and mass transfer effects are accounted for by the model. For more precise results the calculations should involve many elution profiles, including those of pure substances and different component ratios. In this study we checked if the method could also be successfully applied when there is no such possibility.

\subsection{Column model and characterization}

The investigated separation process occured in the gaseous phase. Since, unlike liquids, gases are compressible, the velocity, pressure and temperature are not considered constant $[42,43]$. The model should consist of component and overall mass balance, energy balance, momentum balance and adsorption isotherm model.

To simplify the design of the process it is advantageous to use an inert carrier as a diluent, as done already in [23-25]. For diluted systems, the adsorbed species is present in larger excess of the carrier gas, so changes of gas velocity and temperature due to adsorption and desorption are very small and could be neglected [44]. Therefore, no energy balance is required. If the pressure drop through the bed is low, pressure can be assumed to be constant. In other words, a model with much less parameters like for the liquid phase could be applied, but its applicability needs to be tested. 
Our column model consisted of component mass balance equation represented by the equilibrium dispersive model and the adsorption isotherm equation. Equilibrium dispersive model for a component $i$ in the gas-phase systems (non-constant velocity) is given by the following equation [32, 45, 46]:

$$
\frac{\partial c_{i}}{\partial t}+\frac{\partial\left(u c_{i}\right)}{\partial z}+\frac{1-\varepsilon}{\varepsilon} \frac{\partial q_{i}}{\partial t}=D_{a p p} \frac{\partial^{2} c_{i}}{\partial z^{2}}
$$

where $D_{a p p}, u, c, q, \varepsilon, t$ and $z$ are apparent dispersion coefficient, interstitial velocity of the mobile phase, mobile phase concentration, stationary phase concentration, total bed porosity, time and space coordinate, respectively. Since for diluted systems the velocity could be considered constant, the equation becomes the same as for liquid systems:

$$
\frac{\partial c_{i}}{\partial t}+u \frac{\partial c_{i}}{\partial z}+\frac{1-\varepsilon}{\varepsilon} \frac{\partial q_{i}}{\partial t}=D_{a p p} \frac{\partial^{2} c_{i}}{\partial z^{2}}
$$

The used initial and boundary conditions were: $c(z, 0)=0, c(0, t)=c_{i n j}$, for $t \leq t_{i n j}$ and $c(0, t)=0$, for $t>$ $t_{i n j}\left(t_{i n j}\right.$ is the injection time and $c_{i n j}$ the concentration in the injected sample). In the gas phase typically the solute concentrations are expressed as partial pressure $\left(P_{i}\right)$ or mole fraction $\left(y_{i}\right)$ using the ideal gas law. Therefore following equations were used (in which $V$ is volume, $n$ amount of the substance, $T$ temperature, $R$ gas constant and $P$ total pressure):

$$
P_{i} V=n_{i} R T \quad \Rightarrow \quad c_{i}=\frac{n_{i}}{V}=\frac{P_{i}}{R T}=\frac{y_{i} P}{R T}
$$

For the adsorption of the substances the competitive Langmuir isotherms (with two parameters, $H$ and $b$ ) were chosen:

$$
q_{i}=\frac{H_{i} c_{i}}{1+\sum_{i} b_{i} c_{i}}
$$

We assumed Langmuir model in advance and had shown that it could be applied for both studied systems. The parameter $H$ corresponds to the Henry constant. It was calculated from the retention times of the peaks $\left(t_{R}\right)$ when only small amounts were injected:

$$
H_{i}=\frac{t_{R, i}-t_{0}}{t_{0}} \cdot \frac{\varepsilon}{1-\varepsilon}
$$


The time $t_{0}$ is the column hold-up time. Apparent dispersion coefficient was calculated from the column number of theoretical plates (NTP), mobile phase velocity and column length $(L)$, while the number of theoretical plates can be found by knowing the retention time of the peak and its width at half-height $\left(w_{1 / 2}\right)$ :

$$
\begin{aligned}
& D_{a p p}=\frac{L u}{2 N T P}(6) \\
& N T P \cong 5.54\left(t_{R} / w_{1 / 2}\right)^{2}
\end{aligned}
$$

The total bed porosity was calculated by taking into account the gas compressibility effects - JamesMartin factor $j[47,48]$ from the following expressions (where $\dot{V}$ is volumetric flowrate, $V_{c}$ column volume, $P_{\text {in }}$ inlet pressure in the column and $P_{\text {out }}$ outlet pressure):

$$
\varepsilon=j t_{0} \frac{\dot{V}}{V_{c}} ; \quad j=\frac{3\left[\left(P_{\text {in }} / P_{\text {out }}\right)^{2}-1\right]}{2\left[\left(P_{\text {in }} / P_{\text {out }}\right)^{3}-1\right]}
$$

To simulate a GC system, first it is necessary to calculate the injection parameters for the gas phase. In practice, the sample is injected in the liquid form. Inside the system, due to high temperature, it instantaneously evaporates and travels as gas to the column. The feed concentration and the injected volume in the gas phase can be determined from the ideal gas law (Eq. (3)) and the conservation of the mass during the evaporation [49]:

$$
V_{i n j}^{g a s}=\frac{m_{i n j}}{M} \cdot \frac{R T_{i n}}{P_{i n}}=\frac{V_{i n j}^{l i q} \rho^{l i q}}{M} \cdot \frac{R T_{i n}}{P_{i n}}
$$

The used notation is: $V_{i n j}$ - injected volume, $m_{i n j}$-injected mass, $\rho$ - density, $M$ - molecular weight, $T_{\text {in }}$ - inlet temperature. Superscripts gas and liq stand for gaseous and liquid phase of the sample, respectively.

\subsection{Process performance parameters}

The discussed process performance indicators $[45,50]$ were purity, productivity and recovery. Purity $(P U)$ is expressed as the collected amount of a substance over the complete collected amount. A pure component $i(i=1,2)$ is collected in the time interval defined by the starting $\left(t_{i s}\right)$ and ending $\left(t_{i e}\right)$ cut time (Fig. 1). Component 1 is collected between the start of elution for components 1 and 2, and component 2 between the points of complete elution for the two components. Important for 
defining cut times is the threshold concentration $\left(c_{\text {thresh }}\right)$. It resembles the experimental detection limit, while in simulations it is typically about $1 \%$ of the maximal concentration. The starting cut time is when the concentration of the corresponding component reaches $c_{\text {thresh }}$, while the ending cut time is when it drops below $c_{\text {thresh }}$. The difference between $t_{2 e}$ and $t_{1 s}$ represents the cycle time $\left(t_{c y c l e}\right)$.

Figure 1

Productivity $\left(P R_{i}\right)$ represents collected mass of component $i\left(m_{i, c o l l}\right)$ between the cut times $t_{i s}$ and $t_{i e}$ over the adsorbent volume $\left(V_{a d s}\right)$ and the cycle time:

$$
P R_{i}=\frac{m_{i, c o l l}\left[t_{i s}, t_{i e}\right]}{t_{c y c l e} V_{a d s}}
$$

Recovery $\left(Y_{i}\right)$ of component $i$ is calculated as a ratio of collected amount of that component and its amount injected with the feed mixture $\left(m_{i, i n j}\right)$ :

$$
Y_{i}=\frac{m_{i, \text { coll }}\left[t_{i s}, t_{i e}\right]}{m_{i, i n j}}
$$

\subsection{Scale-up estimation}

In chromatography, scaling up is normally done in a way that the same pattern of the chromatograms in two columns is maintained. To accomplish it, we can use a simple scale-up concept, well-established in the area of liquid chromatography. According to this concept one keeps, besides the particle sizes, the column length constant and increases just the column diameter $(d)$. Attempting to maintain also the characteristic process times and the outlet elution profiles, the injected masses $\left(m_{i n j}=c_{i n j} V_{i n j}\right)$ and the volumetric flowrates have to be increased using the following scale-up rule $[51,52]$ :

$$
\frac{m_{i n j}^{\text {large }}}{m_{i n j}^{\text {small }}}=\frac{\dot{V}^{\text {large }}}{\dot{V}^{\text {small }}}=\left(\frac{d^{\text {large }}}{d^{\text {small }}}\right)^{2}
$$

This equation can be correctly used when the efficiency and porosity are same in both columns. In that case two elution profiles should be identical. 


\subsection{Simulation details}

Process simulations were mainly done in Matlab R2013b (8.2.0.701), MathWorks Inc, Natick, Massachusetts, USA. Differential equations were solved by finite difference method using Rouchon algorithm [53]. For a few fast tests pulse injections were simulated using the ChromSim 1.2 software under Eurochrom 2000 for Windows that also uses integrated Rouchon algorithm. For estimating the parameters of the adsorption isotherm minimization of the following objective function (OF) was done by solving the least-squares problem using Matlab and applying the Nelder-Mead simplex method:

$$
O F=\sum_{k=1}^{n p}\left(\left.c_{i, k}^{\exp }\right|_{z=L}-\left.c_{i, k}^{\text {mod }}\right|_{z=L}\right)^{2}, \quad i=1,2
$$

The superscripts exp and mod refer to the values obtained from the experiments and by using the model, respectively, while $n p$ represents the number of discrete time points.

\section{$4 \quad$ Experimental methods and equipment}

The GC measurements were performed with a gas chromatograph $7890 \mathrm{~A}$ from Agilent Technologies with a build-in flame ionization detector for the signal measurement. Helium (Linde AG, Germany) with $99.99 \%$ purity was used as carrier gas. The racemic mixtures of isoflurane and desflurane (produced by Baxter International Inc., USA) were provided by a local hospital. Four stainless steel columns (inner diameter $d=6 \mathrm{~mm}$, total length $L=4 \cdot 100 \mathrm{~mm}=400 \mathrm{~mm}$ ) were connected in a line. They were heated in the oven of the GC. For the scaled-up column ( $d=15.6 \mathrm{~mm}, L=400 \mathrm{~mm})$ a stainless steel tube was used. It was closed with Swagelok screw capes, in which stainless steel sieves (mash size 10 micron) were fitted at the inlet and outlet. Because of its length it did not fit into the chromatograph. Hence special double jacket was built for tempering the column. A thermal element was placed in the jacket and connected with a process control system (Siemens Simatic 7) to record and control the temperature. As heat transfer fluid we used deionized water, which was heated by Huber Ministat 240.

All columns were mechanically packed with the prepared enantioselective glass beads (particle diameter distribution 52-100 $\mu \mathrm{m}$, mean pore diameter $53 \mathrm{~nm}$, specific pore volume $1.208 \mathrm{~cm}^{-3} \mathrm{~g}$ and porosity 0.727 ). These particles were specially synthesized for this work by the group of Prof. Enke of the University of Leipzig [54-56]. The active surface sites of the glass beads were treated with hexamethydisilazane. Subsequently the particles were coated according to the method described by Schurig [57] with the selector ( $\gamma$-CD derivative developed in [22]) dissolved in polysiloxane SE-54 with a weight ratio of $1: 1$ and a surface concentration of $4.5 \mathrm{mg} \mathrm{m}^{-2}$. When using the mentioned selector, for both anesthetics the elution order is the same [16]: component 1 (first eluting) is S-enantiomer and component 2 (second one) is R-enantiomer. 
The dependency of peak area from the injected mass was linear, so the detector was calibrated by plotting the area versus the known injected amount. Since the enantiomers produced the same signal, only racemic mixtures were used. The total porosity was determined from Eq. (8) using injections of a non-retained substance - methane, chosen based on the previous studies [25, 27-29]. The NTP (Eq. (7)) was determined from the $0.04 \mu \mathrm{L}$ injections, which do not exhibit interference between the peaks. Since the NTP values for component 1 and 2 were slightly different, we used the mean value in the calculations. The parameters and the calculated data are reported in Tab. 1.

\section{Table 1}

The pressure drop, calculated as a difference between the inlet and the outlet pressure, was not very high, especially for desflurane, what justified the use of the simplified models. The flowrate of isoflurane was higher and consequently the pressure drop was larger.

To test the stationary phase and the experimental setup, we performed series of pulse injections with different amounts of racemic mixtures of isoflurane and desflurane (Fig. 2). The pure racemates were injected in the liquid form, so their concentration equals to their density (given in Tab. 1). Different syringes were used for the injections, the smallest one for $0.04-1 \mu \mathrm{L}$ and another two for larger amounts. Due to technical constraints the larger syringes (not completely gas tight) could not be used for desflurane since the substance was evaporating owing to its low boiling point (23.5 으). That problem was not encountered in the case of isoflurane (boiling point $48.5 \mathrm{\circ}$ ). Therefore for desflurane no larger injections than $1 \mu \mathrm{L}$ were possible.

\section{$5 \quad$ Results}

This section provides the results from the experimental studies and process simulation in order to improve the performance characteristics. Some more details could be found in [58].

\subsection{Experimental results}

The elution profiles of isoflurane and desflurane resulting from different pulse injections are shown in Fig. 2. We were able to provide good separation of the enantiomers of both anesthetics.

Figure 2

The pulse injections were further used to estimate the isotherms and validate the results from the simulation study. To minimize the carrier gas consumption and maximize the production, the process was designed as a series of consecutive injections timed so that one elution profile starts when the previous peak ends. 


\subsection{Determination of the adsorption isotherms}

Prior to isotherm estimation the Henry constants (Eq. (5)) were calculated using the elution profile of $0.04 \mu \mathrm{L}$ injections. From Henry constants the selectivity $\alpha=H_{2} / H_{1}$ was determined. In the next step the peak-fitting method was applied to estimate the complete adsorption isotherms. The values of the parameters are presented in Tab. 2 .

Table 2

The estimated single component Langmuir isotherms are shown in Fig. 3 for the concentration range that corresponds to the values in the elution profiles. Obviously isoflurane is stronger bound on the stationary phase compared to desflurane. The effect of competition is captured by Eq. (4).

Figure 3

The separation process was simulated using the determined isotherms. Comparison of experimental and simulated profiles is given in Fig. 4 . The figure shows two examples for isoflurane $(1 \mu \mathrm{L}$ and $5 \mu \mathrm{L}$ injections) and for desflurane the largest experimentally achievable injection $(1 \mu \mathrm{L})$. The simulated and experimental profiles corresponded well to each other. There were small discrepancies of the same form for all cases mainly due to the fact that in the simulation the same NTP was taken for both enantiomers, although it was slightly larger for component 1 . Therefore simulations predicted higher degree of dispersion for component 1 and lower for 2 than it was in the reality.

Figure 4

Since the differences between simulation and experiments are not significant, the matching is considered very good and the calculated isotherms could be used to correctly predict the separation. We showed that the peak-fitting method was reliable even when no pure components were accessible. Since the peak-fitting method requires adopting a column model in advance, its application also served as an evidence that the equilibrium dispersive model with assumed constant mobile phase velocity, pressure and temperature can be used to describe the GC process for diluted systems.

\subsection{Evaluation of the process performance}

Since the anesthetics in racemic form can be obtained from hospitals in larger amounts, while there is no access to pure enantiomers, our goal was to maximize the purity and productivity of the single components. The "touching-bands" case provides the best separation, but to obtain optimal production, one must work in the so-called overloaded conditions [32]. We performed a series of volume overloading simulation tests to examine the effect of different injection amounts on the productivity and recovery, while the purity was maintained above $99 \%$. With the available equipment it was not possible to experimentally examine the injections larger than $5 \mu \mathrm{L}$ for 
isoflurane and $1 \mu \mathrm{L}$ for desflurane. To check if the productivity could still be improved simulation tests were conducted for even higher injected amounts, i.e. for the range $0.038-23 \mathrm{mg}$ of one enantiomer (0.076- $46 \mathrm{mg}$ of racemate). This corresponds to $0.051-30 \mu \mathrm{L}$ injections in the liquid phase of isoflurane and $0.052-31 \mu \mathrm{L}$ of desflurane. Sample concentration was kept the same as in the experiments (Table 1). The threshold value was $c_{\text {thresh }}=10^{-5} \mathrm{~g} \mathrm{~L}^{-1}$.

The predicted changes of productivity (Eq. (10)) and recovery (Eq. (11)) with the injected amount are shown in Fig. 5 and 6. The experimental values are given along with the simulation results. Since in the experiments the exact shape of the single component peaks was not known, we assumed it according to the overall profile shape. The comparison showed that the experimental and simulated values matched each other very well. This was one way of validating the predictions regarding model and isotherm determination.

\section{Figure 5}

\section{Figure 6}

Because of the experimental constraints the matching for isoflurane could be proved in the range from 0 to the maximum productivity point. Since the behavior after reaching the maximum is not of practical importance, the validation was successful. For desflurane only the experimental values in the low-amounts range could be calculated, but knowing that the process was the same and the calculated productivity is in the expected range compared to the isoflurane (including different cycle times), it can be considered that the predictions are accurate.

For both anesthetics, by increasing the injected amount, productivity started to increase until the point when the enantiomers could not be well separated. After reaching the maximum, productivity began to decrease. For the first component $(S)$ it approached zero, while for component $2(R)$ it decreased slowly, but indefinitely. The reason is that the fronts of both peaks move forward as the injected mass increases, but their tails that correspond to the state of infinite dilution remain constant. The similar productivity curves were observed in the literature, e.g. in [59]. As expected, recovery decreased by increasing the injected mass, since for this type of systems the peak resolution becomes worse for larger feed amounts.

The values of productivity, recovery and purity are presented in Tab. 3. The parameters are given for the "touching-bands" case and when the production maxima of $\mathrm{S}$ - and R-enantiomer were obtained. The productivity of R-component is only slightly higher for the case when R-enantiomer maximum is achieved, than when achieving it for S. For S-enantiomer this difference is greater. Since the values of recovery are not very different, the point with the highest production of S-enantiomer was selected as optimal.

Table 3 
A way to additionally increase the productivity is to lower the required purity. There are examples where the achieved purity of fluorinated anesthetics was not as high as in this work, e.g. [24, 25]. For our system when the wanted purity was lowered to $90 \%$, the productivity of both isoflurane enantiomers reached the value of $4.97 \mathrm{~g} \mathrm{~h}^{-1} \mathrm{~L}_{\text {ads }}{ }^{-1}$, while the recovery increased to $92 \%$. For desflurane productivity of both enantiomers increased to $10.9 \mathrm{~g} \mathrm{~h}^{-1} \mathrm{Lads}^{-1}$, and recovery to $91 \%$.

To evaluate the developed process, its performance can be compared to the literature data. For comparison we selected all publications with reported productivity values. The checked processes were batch GC $[23,24]$ and SMB separation [25]. In Tab. 4 the literature data are compared to the values obtained in our work.

\section{Table 4}

The comparison revealed that purity achieved in our work is comparable or higher than in the other processes. Recovery is higher only for isoflurane separation using SMB [25], where the purity is lower for both enantiomers. Regarding productivity, in our work larger amount of pure enantiomers of both anesthetics could be obtained.

\subsection{Estimation of column scale-up}

We set as a goal to provide in our laboratory in a future exploitation of these results one gram of pure enantiomers of the fluorinated anesthetics in one day. An obvious way to obtain more product per time is to process more feed using larger columns. We did calculations and predicted process performance for a column of the same length $(400 \mathrm{~mm})$ as the column used in the starting experiments, but with larger diameter $(1.56 \mathrm{~cm})$. It is denoted as $C 2$, while the small column $(d=0.6$ $\mathrm{cm}$ ) is named $\mathrm{C} 1$.

The optimal case, with maximal production of S-enantiomer, was explored. First the volumetric flowrate and injected volume and mass were calculated from Eq. (12). Then, the performance characteristics were determined by simulating the process. Tab. 5 lists the obtained results. By using this scale-up rule purity, recovery and productivity should remain the same as they were for the smaller column. What increases is the overall production, expressed as collected mass per hour $\left(m_{\text {coll/h }}\right)$. As an illustration also the time for collecting one gram of pure enantiomer $\left(t\left(m_{\text {coll }}=1 \mathrm{~g}\right)\right)$ is presented in Tab. 5.

\section{Table 5}

These results show that an increase of the column diameter from $0.6 \mathrm{~cm}$ to $1.56 \mathrm{~cm}$ gives the possibility to collect within a reasonable time period (about $24 \mathrm{~h}$ for $1 \mathrm{~g}$ of isoflurane enantiomers and $11 \mathrm{~h}$ for desflurane) sufficient amounts of pure enantiomers that can be used for further analyses. 
To perform a first check of our predictions, a few validation experiments were conducted. By applying the scaling rule given by Eq. (12), the chromatograms from columns with the same length should be identical. The column C2 was used for pulse injections according to the conditions in Tab. 5. Fig. 7 shows the comparison of the peaks recorded for two column scales. The experimental values of the flowrate and injected amount are given in the caption of the figure (they are slightly different from the calculated ones due to equipment constraints). For the sake of simplicity only the experimental profiles are given. The simulation for both columns produced identical elution profiles, which were already compared to the experiments in Fig. 4 for column $\mathrm{C} 1$.

The agreement between the peaks measured and predicted is very good. The main deviation is in the peak position. It could originate from differences in the packing of two columns. Another reason could be that the injection amounts and flowrates were not completely correct. Furthermore, since there was a time difference between performing experiments with small- and larger-scale columns, the particles and the selector were prepared separately, although the same procedure was applied.

The presented results of the experiments with the larger column show that the simulation could provide correct predictions, which means that our assumptions are reasonable. At the same time, these experiments represent the first step for the successful production of pure enantiomers of the anesthetic gases.

Figure 7

\section{Outlook}

After separating mixtures it is typically an important task is to isolate the pure substances from the mobile phase. For that purpose, condensation of the anesthetics in cooling traps was applied in previous studies [16, 23-25, 27-29]. Since the substances are highly diluted, deep cooling (with liquid nitrogen) had to be used. As an alternative, periodically operated capture columns can be used. After the separation the resulting chromatogram contains three fractions, two pure components and the mixture. Our concept is to use three capture columns for storing each of these fractions for a larger number of cycles. When these capture columns are completely saturated, a regeneration (harvesting) step can be performed, where streams with concentrated target substances are produced. Then in the last step, which involves cooling traps, only moderate cooling (around $0 \stackrel{\circ}{\circ}$ ) is needed to provide the condensation of the anesthetics [60] and to finally separate them from the carrier gas. Using the described strategy, we could already produce in preliminary runs pure enantiomers of both anesthetics, as will be reported soon. 


\section{Conclusions}

In the presented work the enantioseparation of isoflurane and desflurane using gas chromatography was investigated. A stationary phase consisting of porous glass beads coated with chiral selector based on $\gamma$-cyclodextrin [22] was prepared, characterized and applied for separating the enantiomers. Applying the knowledge of the adsorption isotherms, the separation process could be simulated using the equilibrium dispersive model. The analyzed process was classical discontinuous (batch) gas chromatography with repetitive injections. Different injected amounts were studied in order to identify the maximal productivity and high purity (over $99 \%$ ). It has been predicted that it should be possible to produce about $3 \mathrm{~g} \mathrm{~h}^{-1} \mathrm{~L}_{\mathrm{ads}}{ }^{-1}$ of isoflurane enantiomers and about $6.5 \mathrm{~g} \mathrm{~h}^{-1} \mathrm{~L}_{\mathrm{ads}}{ }^{-1}$ of desflurane enantiomers. These productivities are judged to be enough to obtain with a lab-scale column sufficient amounts of pure enantiomers to test their specific effects.

\section{Acknowledgment}

The authors thank the German Research Foundation (DFG) for the financial funding in the frame of the Priority Program 1570 and Dr. Christian Küster (University of Leipzig) for the preparation of the glass supports. This research is also supported by the International Max Planck Research School Magdeburg, Germany.

The authors have declared no conflict of interest.

\section{Symbols used}

$\begin{array}{lll}b & {\left[\mathrm{~L} \mathrm{~g}^{-1}\right]} & \text { Langmuir isotherm parameter } \\ c & {\left[\mathrm{~g} \mathrm{~L}^{-1}\right]} & \text { Mobile phase concentration } \\ c_{\text {inj }} & {\left[\mathrm{g} \mathrm{L}^{-1}\right]} & \text { Feed (injected) concentration } \\ c_{\text {thresh }} & {\left[\mathrm{g} \mathrm{L}^{-1}\right]} & \text { Threshold concentration } \\ d & {\left[\mathrm{~cm}^{-1}\right.} & \text { Column inner diameter } \\ D_{a p p} & {\left[\mathrm{~m}^{2} \mathrm{~s}^{-1}\right]} & \text { Apparent dispersion coefficient } \\ H & {[-]} & \text { Henry constant } \\ j & {[-]} & \text { James-Martin factor } \\ L & {[\mathrm{~cm}]} & \text { Column length } \\ M & {\left[\mathrm{~g} \mathrm{~mol}^{-1}\right]} & \text { Molecular weight } \\ m_{\text {coll }} & {[\mathrm{g}]} & \text { Collected mass } \\ m_{\text {coll/hh}} & {[\mathrm{g}]} & \text { Collected mass per hour }\end{array}$

This article is protected by copyright. All rights reserved. 


\begin{tabular}{|c|c|c|}
\hline$m_{i n j}$ & {$[g]$} & Injected mass \\
\hline$n$ & {$[\mathrm{~mol}]$} & Substance amount \\
\hline$n p$ & {$[-]$} & Number of time points \\
\hline NTP & {$[-]$} & Number of theoretical plates \\
\hline$P$ & {$[\mathrm{kPa}]$} & Pressure \\
\hline$P_{\text {in }}$ & [kPa] & Inlet pressure \\
\hline$P_{\text {out }}$ & {$[\mathrm{kPa}]$} & Outlet pressure \\
\hline$P R$ & {$\left[\mathrm{~g} \mathrm{~h}^{-1} \mathrm{~L}_{\mathrm{ads}}{ }^{-1}\right]$} & Productivity \\
\hline$P U$ & {$[-]$} & Purity \\
\hline$q$ & {$\left[\mathrm{~g} \mathrm{~L}^{-1}\right]$} & Stationary phase concentration \\
\hline$R$ & {$\left[\mathrm{~J} \mathrm{~mol}^{-1} \mathrm{~K}^{-1}\right]$} & Gas constant \\
\hline$t$ & {$[\mathrm{~min}]$} & Time \\
\hline$T$ & {$\left[{ }^{\circ} \mathrm{C}\right]$} & Temperature \\
\hline$t_{0}$ & {$[\mathrm{~min}]$} & Column hold-up time \\
\hline$t_{\text {cycle }}$ & {$[\mathrm{min}]$} & Cycle time \\
\hline$t_{e}$ & {$[\mathrm{~min}]$} & Ending cut time \\
\hline$T_{\text {in }}$ & {$\left[{ }^{\circ} \mathrm{C}\right]$} & Inlet temperature \\
\hline$t_{i n j}$ & {$[\mathrm{~min}]$} & Injection time \\
\hline$t_{R}$ & {$[\mathrm{~min}]$} & Retention time \\
\hline$t_{s}$ & {$[\mathrm{~min}]$} & Starting cut time \\
\hline$u$ & {$\left[\mathrm{~m} \mathrm{~s}^{-1}\right]$} & Interstitial velocity of the mobile phase \\
\hline$V$ & {$\left[\mathrm{~m}^{3}\right]$} & Volume \\
\hline$\dot{V}$ & {$\left[\mathrm{~mL} \mathrm{~min} \min ^{-1}\right]$} & Volumetric flowrate \\
\hline$V_{a d s}$ & {$[\mathrm{~mL}]$} & Adsorbent volume \\
\hline$V_{c}$ & {$[\mathrm{~mL}]$} & Column volume \\
\hline$V_{i n j}$ & {$[\mu L]$} & Injected volume \\
\hline$w_{1 / 2}$ & {$[\min ]$} & Peak width at its half-height \\
\hline$y$ & {$[-]$} & Mole fraction \\
\hline$Y$ & {$[-]$} & Recovery \\
\hline$z$ & {$[\mathrm{~m}]$} & Space coordinate \\
\hline
\end{tabular}

\section{Greek letters}

$\alpha \quad[-] \quad$ Selectivity 


$\begin{array}{lll}\varepsilon & {[-]} & \text { Total bed porosity } \\ \rho & {\left[\mathrm{g} \mathrm{L}^{-1}\right]} & \text { Density }\end{array}$

\section{Sub- and superscripts}

$\begin{array}{ll}\text { ads } & \text { Adsorbent } \\ \text { exp } & \text { Experiment } \\ \text { gas } & \text { Gaseous phase } \\ i & \text { Component }(i=1,2) \\ \text { large } & \text { Larger column } \\ \text { liq } & \text { Liquid phase } \\ \text { mod } & \text { Model } \\ \text { small } & \text { Small column }\end{array}$

\section{Abbreviations}

$\begin{array}{ll}\text { CD } & \text { Cyclodextrin } \\ \text { GC } & \text { Gas chromatography } \\ \text { SMB } & \text { Simulated moving bed }\end{array}$

\section{References}

[1] D. A. Sidebotham, S. A. Schug, Clinical and Experimental Pharmacology and Physiology, Review, 1997, 24 (2), 126-130.

[2] P. L. Polavarapu, A. L. Cholli, G. Vernice, Journal of the American Chemical Society, Article, 1992, 114 (27), 10953-10955. DOI: 10.1021/ja00053a038

[3] V. Schurig, M. Juza, B. S. Green, J. Horakh, A. Simon, Angewandte Chemie (International Edition in English), Article, 1996, 35 (15), 1680-1682.

[4] N. P. Franks, W. R. Lieb, Science, Article, 1991, 254 (5030), 427-430.

[5] B. Harris, E. Moody, P. Skolnick, Eur. J. Pharmacol., Article, 1992, 217 (2-3), 215-216. DOI: 10.1016/0014-2999(92)90875-5

[6] R. Dickinson, I. White, W. R. Lieb, N. P. Franks, Anesthesiology, Article, 2000, 93 (3), 837-843.

[7] A. C. Hall, W. R. Lieb, N. P. Franks, British Journal of Pharmacology, 1994, 112 (3), 906-910. DOI: 10.1111/j.1476-5381.1994.tb13166.x 
[8] E. J. Moody, B. D. Harris, P. Skolnick, Trends in Pharmacological Sciences, Review, 1994, 15 (10), 387-391. DOI: 10.1016/0165-6147(94)90160-0

[9] H. Y. Aboul-Enein, J. Bojarski, J. Szymura-Oleksiak, Biomed. Chromatogr., Review, 2000, 14 (4), 213-218. DOI: 10.1002/1099-0801(200006)14:4<213::AID-BMC975>3.0.CO;2-R

[10] L. A. Rozov, C. G. Huang, D. F. Halpern, G. G. Vernice, K. Ramig, Tetrahedron Asymmetry, Article, 1997, 8 (18), 3023-3025. DOI: 10.1016/S0957-4166(97)00382-0

[11] H. A. Haeberle, H. G. Wahl, G. Aigner, K. Unertl, H. J. Dieterich, Eur. J. Anaesthesiol., Article, 2004, 21 (2), 144-150. DOI: 10.1017/S026502150400211X

[12] R. Schmidt, H. G. Wahl, H. Häberle, H. J. Dieterich, V. Schurig, Chirality, Article, 1999, 11 (3), 206-211. DOI: 10.1002/(SICI)1520-636X(1999)11:3<206::AID-CHIR6>3.0.CO;2-R

[13] M. Juza, H. Jakubetz, H. Hettesheimer, V. Schurig, Journal of Chromatography B: Biomedical Sciences and Applications, Article, 1999, 735 (1), 93-102. DOI: 10.1016/S0378-4347(99)00409-0

[14] C. G. Huang, L. A. Rozov, D. F. Halpern, G. G. Vernice, Journal of Organic Chemistry, Article, 1993, 58 (26), 7382-7387.

[15] K. Ramig, Synthesis, Article, 2002, (17), 2627-2631.

[16] V. Schurig, in Differentiation of Enantiomers I, (Ed: V. Schurig), Springer, Heidelberg, 2013, 153-207.

[17] W. Saenger, Angew. Chem. Int. Ed. Engl., 1980, 19 (5), 344-362.

[18] V. Schurig, H. P. Nowotny, Angewandte Chemie - International Edition in English, Review, 1990, 29 (9), 939-957.

[19] V. Schurig, H. Grosenick, B. S. Green, Angew. Chem. Int. Ed. Engl., 1993, 32 (11), 1662-1663.

[20] A. Shitangkoon, D. U. Staerk, G. Vigh, J. Chromatogr. A, Article, 1993, 657 (2), 387-394. DOI: 10.1016/0021-9673(93)80294-I

[21] J. Meinwald, W. R. Thompson, D. L. Pearson, W. A. König, T. Runge, W. Francke, Science, Article, 1991, 251 (4993), 560-561.

[22] W. A. König, R. Krebber, P. Mischnick, Journal of High Resolution Chromatography, 1989, 12 (11), 732-738. DOI: 10.1002/jhrc.1240121108

[23] V. Schurig, H. Grosenick, J. Chromatogr. A, 1994, 666, 617-625.

[24] M. Juza, E. Braun, V. Schurig, J. Chromatogr. A, Article, 1997, 769 (1), 119-127. DOI: 10.1016/S0021-9673(97)00024-1

[25] G. Biressi, A. Rajendran, M. Mazzotti, M. Morbidelli, Separation Science and Technology, 2002, 37 (11), 2529-2543. DOI: 10.1081/ss-120004451

[26] T. Munkelt, C. Küster, C. Hamel, D. Enke, A. Seidel-Morgenstern, Chemie Ingenieur Technik, 2013, 85 (11), 1686-1693. DOI: 10.1002/cite.201300076

[27] M. Juza, O. Di Giovanni, G. Biressi, V. Schurig, M. Mazzotti, M. Morbidelli, J. Chromatogr. A, Article, 1998, 813 (2), 333-347. DOI: 10.1016/S0021-9673(98)00322-7

[28] G. Biressi, F. Quattrini, M. Juza, M. Mazzotti, V. Schurig, M. Morbidelli, Chemical Engineering Science, 2000, 55 (20), 4537-4547. DOI: http://dx.doi.org/10.1016/S0009-2509(00)00109-3

[29] G. Biressi, M. Mazzotti, M. Morbidelli, J. Chromatogr. A, 2002, 957 (2), 211-225. DOI: http://dx.doi.org/10.1016/S0021-9673(02)00319-9 
[30] J. Bentley, Q. Huang, Y. Kawajiri, M. Eic, A. Seidel-Morgenstern, Adsorption, 2011, 17 (1), 159170. DOI: $10.1007 /$ s10450-010-9299-x

[31] K. P. Kostroski, P. C. Wankat, Industrial and Engineering Chemistry Research, Article, 2008, 47 (9), 3138-3149. DOI: 10.1021/ie071000b

[32] G. Guiochon, A. Felinger, D. G. Shirazi, A. M. Katty, Fundamentals of Preparative and Nonlinear Chromatography, 2nd ed., Academic Press, Boston 2006.

[33] A. Seidel-Morgenstern, J. Chromatogr. A, 2004, 1037 (1-2), 255-272. DOI: 10.1016/j.chroma.2003.11.108

[34] A. Cavazzini, A. Felinger, K. Kaczmarski, P. Szabelski, G. Guiochon, J. Chromatogr. A, Article, 2002, 953 (1-2), 55-66. DOI: 10.1016/S0021-9673(02)00150-4

[35] P. Forssén, J. Lindholm, T. Fornstedt, J. Chromatogr. A, Article, 2003, 991 (1), 31-45. DOI: 10.1016/S0021-9673(03)00213-9

[36] A. Felinger, D. Zhou, G. Guiochon, J. Chromatogr. A, 2003, 1005 (1-2), 35-49. DOI: 10.1016/s0021-9673(03)00889-6

[37] I. Mutavdžin, A. Seidel-Morgenstern, M. Petkovska, Chemical Engineering Science, Article, 2013, 89, 21-30. DOI: 10.1016/j.ces.2012.11.032

[38] E. V. Dose, S. Jacobson, G. Guiochon, Analytical chemistry, 1991, 63, 833-839.

[39] D. Antos, W. Piątkowski, K. Kaczmarski, Acta Chromatographica, Article, 1999, (9), XI-XII.

[40] F. James, M. Sepúlveda, F. Charton, I. Quinones, G. Guiochon, Chemical Engineering Science, Article, 1999, 54 (11), 1677-1696. DOI: 10.1016/S0009-2509(98)00539-9

[41] P. Forssén, R. Arnell, T. Fornstedt, Computers and Chemical Engineering, 2006, 30 (9), 13811391. DOI: $10.1016 /$ j.compchemeng.2006.03.004

[42] L. Jacob, G. Guiochon, J. Chromatogr. A, Article, 1972, 65 (1), 19-27. DOI: 10.1016/S00219673(00)86914-9

[43] J. Roles, G. Guiochon, Journal of Chromatography, 1992, 589, 223-230.

[44] D. M. Ruthven, S. Farooq, K. S. Knaebel, Pressure swing adsorption, VCH Publishers, 1994.

[45] Preparative chromatography, 2., completely rev. and updated ed. (Eds: H. Schmidt-Traub, M. Schulte, A. Seidel-Morgenstern), Wiley-VCH, Weinheim, 2013.^

[46] D. M. Ruthven, Principles of adsorption and adsorption processes, Wiley, New York 1984.

[47] A. T. James, A. J. Martin, The Biochemical journal, Article, 1952, 50 (5), 679-690.

[48] R. Kaiser, Gas Phase Chromatography, Volume I (translated by P.H. Scott), Butterworths, London 1963.

[49] J. L. Anderson, A. Berthod, V. Pino, A. M. Stalcup, Gas chromatography, sub-and supercritical fluid chromatography, First edition ed., Analytical separation science, Vol. Volume 3, Wiley-VCH Verlag GmbH \& Co. KGaA, Weinheim 2015.

[50] S. Golshan-Shirazi, G. Guiochon, Analytical chemistry, 1989, 61 (11), 1276-1287.

[51] C. Heuer, P. Hugo, G. Mann, A. Seidel-Morgenstern, J. Chromatogr. A, 1996, 752 (1-2), 19-29. DOI: http://dx.doi.org/10.1016/S0021-9673(96)00496-7

[52] K. Unger, Handbuch der HPLC, Teil 2: Präparative Säulenflüssig-Chromatographie, GIT Verlag, Darmstadt 1994. 
[53] P. Rouchon, M. Schonauer, P. Valentin, G. Guiochon, Separation Science and Technology, 1987, 22 (8-10), 1793-1833. DOI: 10.1080/01496398708057614

[54] M. Münzner, G. Dornberg, C. Küster, D. Enke, Chem Ing Tech, Article, 2016, 88 (11), 17611769. DOI: $10.1002 /$ cite. 201600053

[55] C. Küster, B. Reinhardt, M. Fröba, D. Enke, Zeitschrift fur Anorganische und Allgemeine Chemie, Article, 2014, 640 (3-4), 565-569. DOI: 10.1002/zaac.201300456

[56] A. Inayat, B. Reinhardt, J. Herwig, C. Küster, H. Uhlig, S. Krenkel, E. Raedlein, D. Enke, New Journal of Chemistry, Review, 2016, 40 (5), 4095-4114. DOI: 10.1039/c5nj03591k

[57] V. Schurig, M. Schleimer, S. Mayer [Patent No. DE4324636], DE4324636, 1994.

[58] I. Mutavdžin, Ph.D. Thesis, Otto von Guericke University Magdeburg 2017.

[59] A. Felinger, G. Guiochon, J. Chromatogr. A, 1992, 591 (1-2), 31-45. DOI: 10.1016/00219673(92)80220-0

[60] J. Jänchen, J. B. Brückner, H. Stach, Eur. J. Anaesthesiol., Article, 1998, 15 (3), 324-329.

\section{Figure legends}

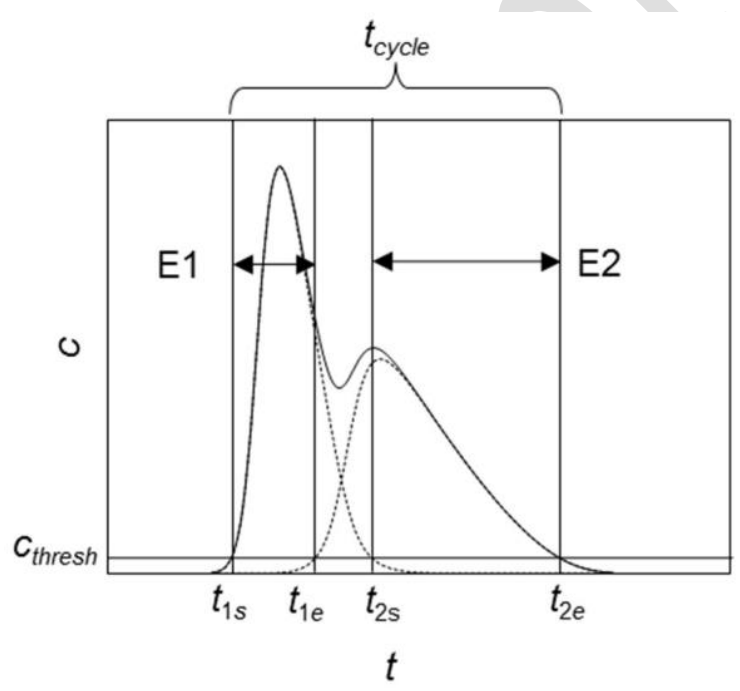

Figure 1. Representation of a racemic mixture elution profile with marked cycle time, threshold concentration ( $\left.c_{\text {thresh }}\right)$ and four characteristic cut times ( $t_{1 s}$ and $t_{1 e}$ for enantiomer 1 and $t_{2 s}$ and $t_{2 e}$ for enantiomer 2), between which the pure enantiomers (E1 and E2) are collected. 

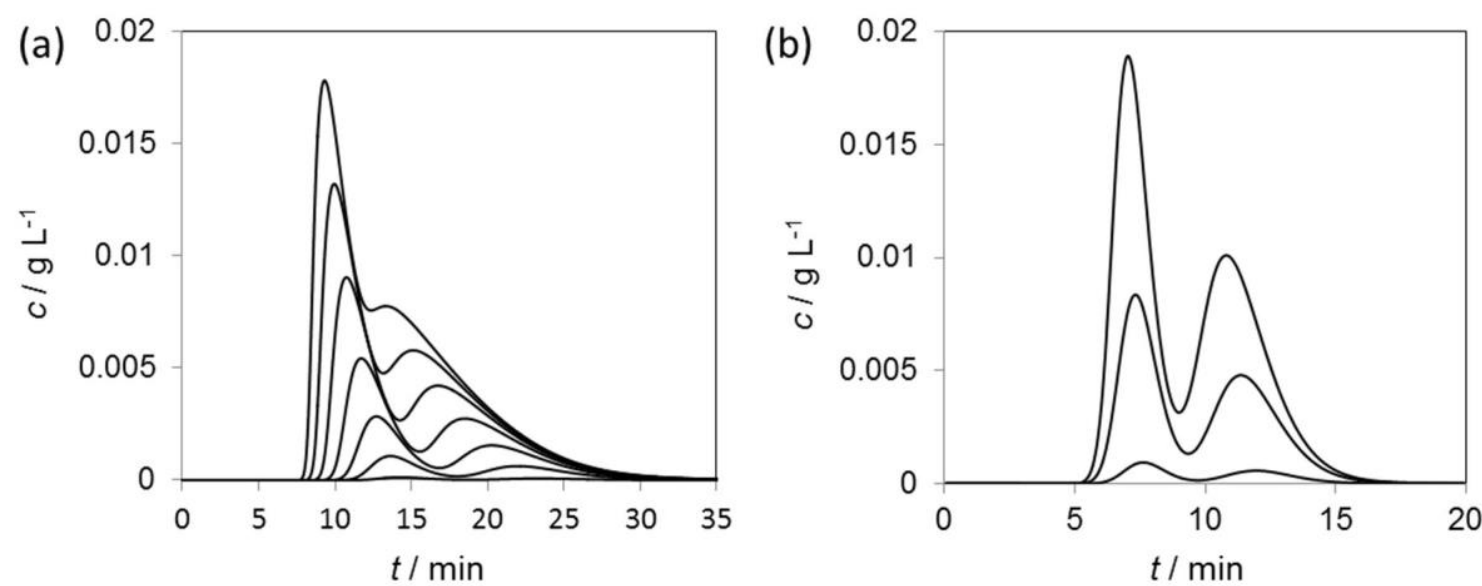

Figure 2. Elution profiles obtained by increasing the injection volumes of the pure racemate (in the brackets the injected mass of one enantiomer is given) for: (a) Isoflurane: $0.04 \mu \mathrm{L}(0.030 \mathrm{mg}), 0.4 \mu \mathrm{L}$ (0.30 mg), $1 \mu \mathrm{L}$ (0.75 mg), $2 \mu \mathrm{L}(1.50 \mathrm{mg}), 3 \mu \mathrm{L}(2.15 \mathrm{mg}), 4 \mu \mathrm{L}(2.98 \mathrm{mg}), 5 \mu \mathrm{L}$ (3.84 mg); (b) Desflurane: $0.04 \mu \mathrm{L}(0.038 \mathrm{mg}), 0.4 \mu \mathrm{L}(0.382 \mathrm{mg}), 1 \mu \mathrm{L}(0.70 \mathrm{mg})$. Sample volumes were measured in the liquid phase. The temperature was $28{ }^{\circ} \mathrm{C}$ and the flowrate $71 \mathrm{~mL} \mathrm{~min}^{-1}$ for isoflurane and $21 \mathrm{~mL}$ $\min ^{-1}$ for desflurane.
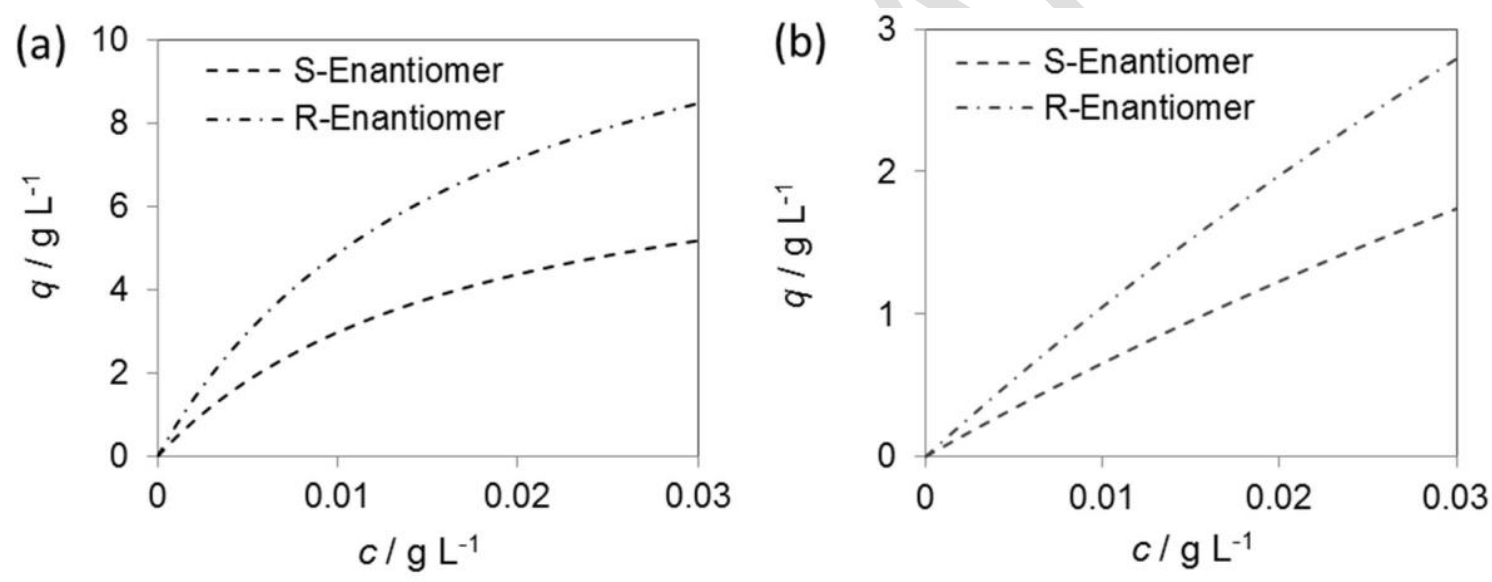

Figure 3. Single component Langmuir adsorption isotherms of: (a) Isoflurane enantiomers; (b) Desflurane enantiomers. S corresponds to component 1 and $\mathrm{R}$ to component 2 for both substances. Isotherm parameters were determined at $28^{\circ} \mathrm{C}$ and are given in Tab. 2. 

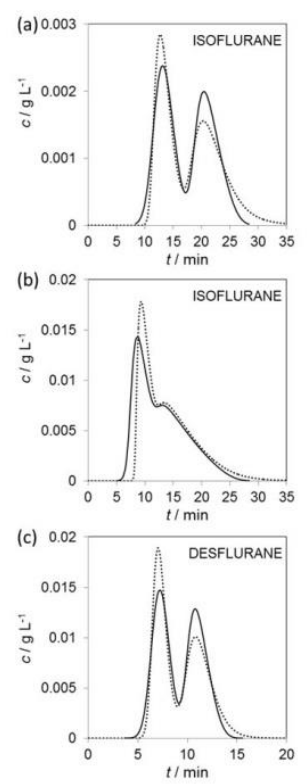

Figure 4. Comparison of the experimental (dotted line) and simulated (solid line) elution profiles for different injection volumes: (a) Isoflurane $1 \mu \mathrm{L}$ ( $0.75 \mathrm{mg}$ of one enantiomer); (b) Isoflurane $5 \mu \mathrm{L}$ (3.84 $\mathrm{mg}$ of one enantiomer); (c) Desflurane $1 \mu \mathrm{L}$ ( $0.70 \mathrm{mg}$ of one enantiomer). Pure racemic mixtures were injected in the liquid phase. The flowrate was $71 \mathrm{~mL} \mathrm{~min}^{-1}$ for isoflurane experiments and $21 \mathrm{~mL}$ $\min ^{-1}$ for desflurane.
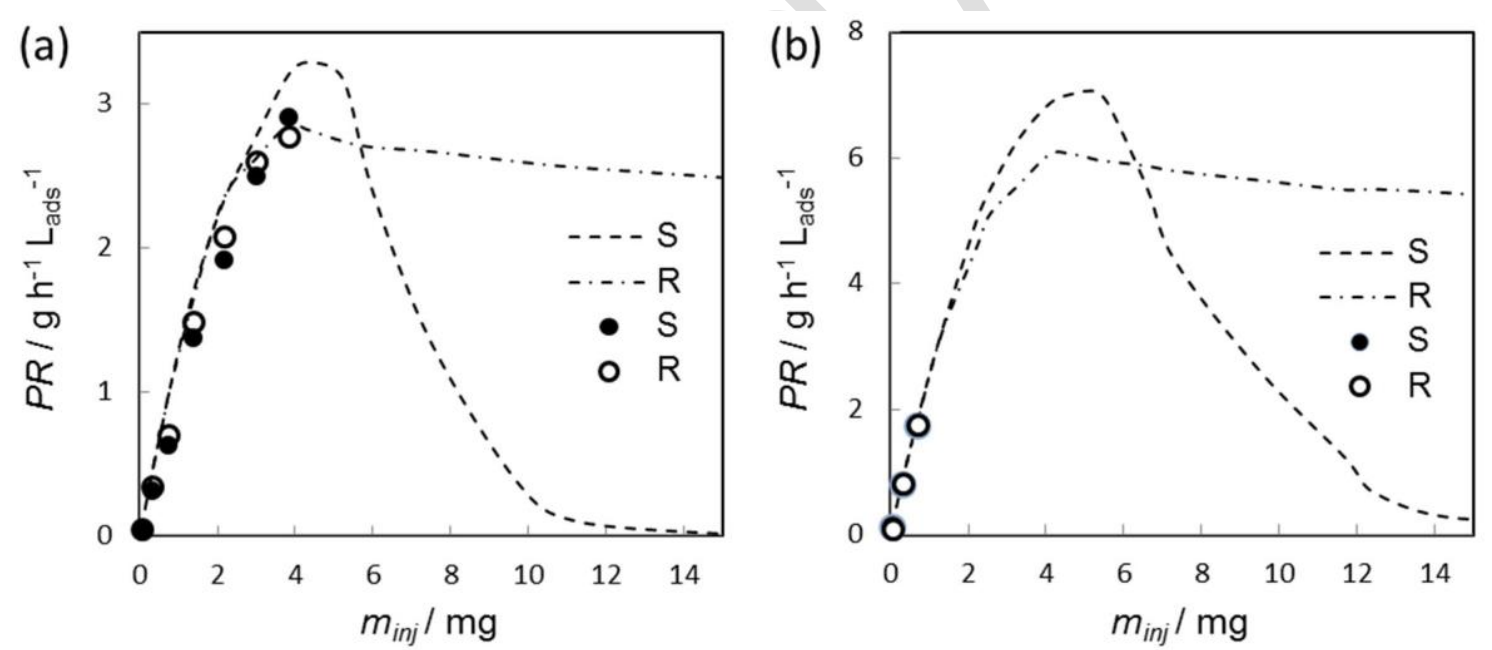

Figure 5. Dependency of the productivity of: (a) Isoflurane; (b) Desflurane enantiomers ( $\mathrm{S}$ and $\mathrm{R}$ ) on the injected amount of one enantiomer. The volumetric flowrate was $71 \mathrm{~mL} \mathrm{~min}^{-1}$ for isoflurane and $21 \mathrm{~mL} \mathrm{~min}^{-1}$ for desflurane. Lines represent the results from the simulation study and symbols the values estimated from the experiments. 

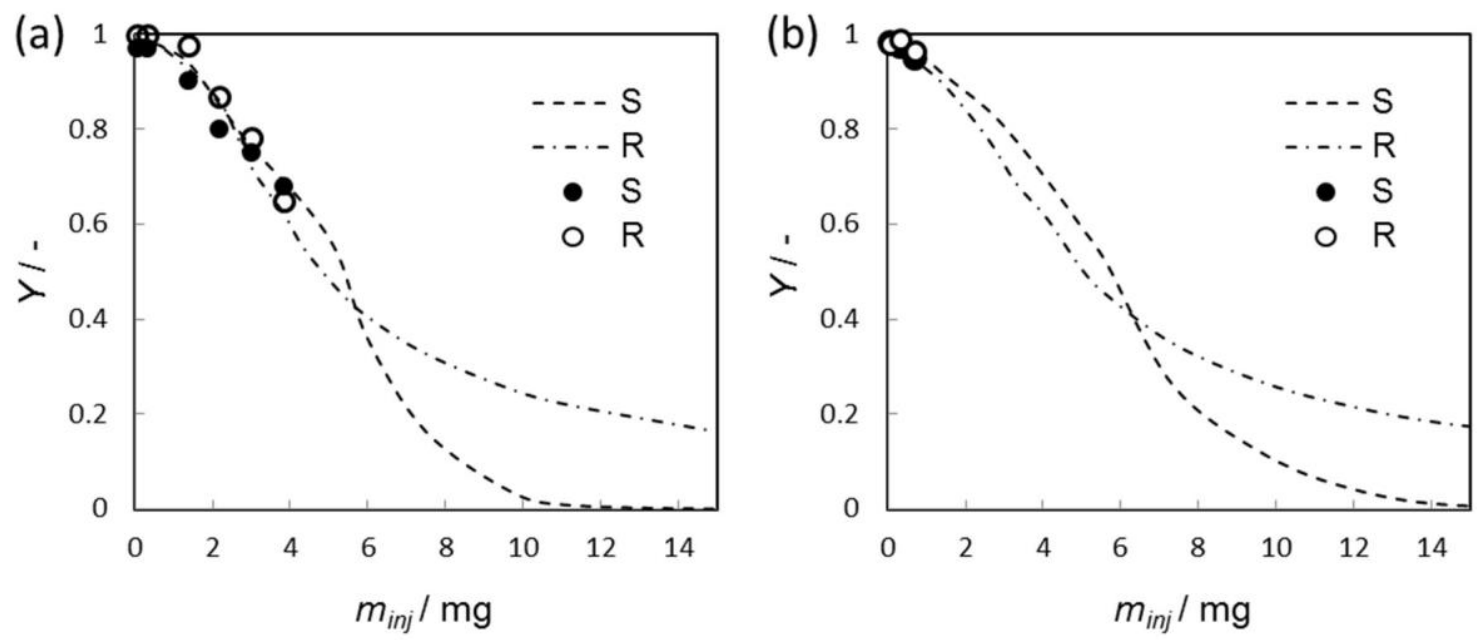

Figure 6. Dependency of the recovery of: (a) Isoflurane; (b) Desflurane enantiomers ( $S$ and $R$ ) on the injected amount of one enantiomer. The volumetric flowrate was $71 \mathrm{~mL} \mathrm{~min}$ for isoflurane and 21 $\mathrm{mL} \mathrm{min}^{-1}$ for desflurane. Lines represent the results from the simulation study and symbols the values estimated from the experiments.
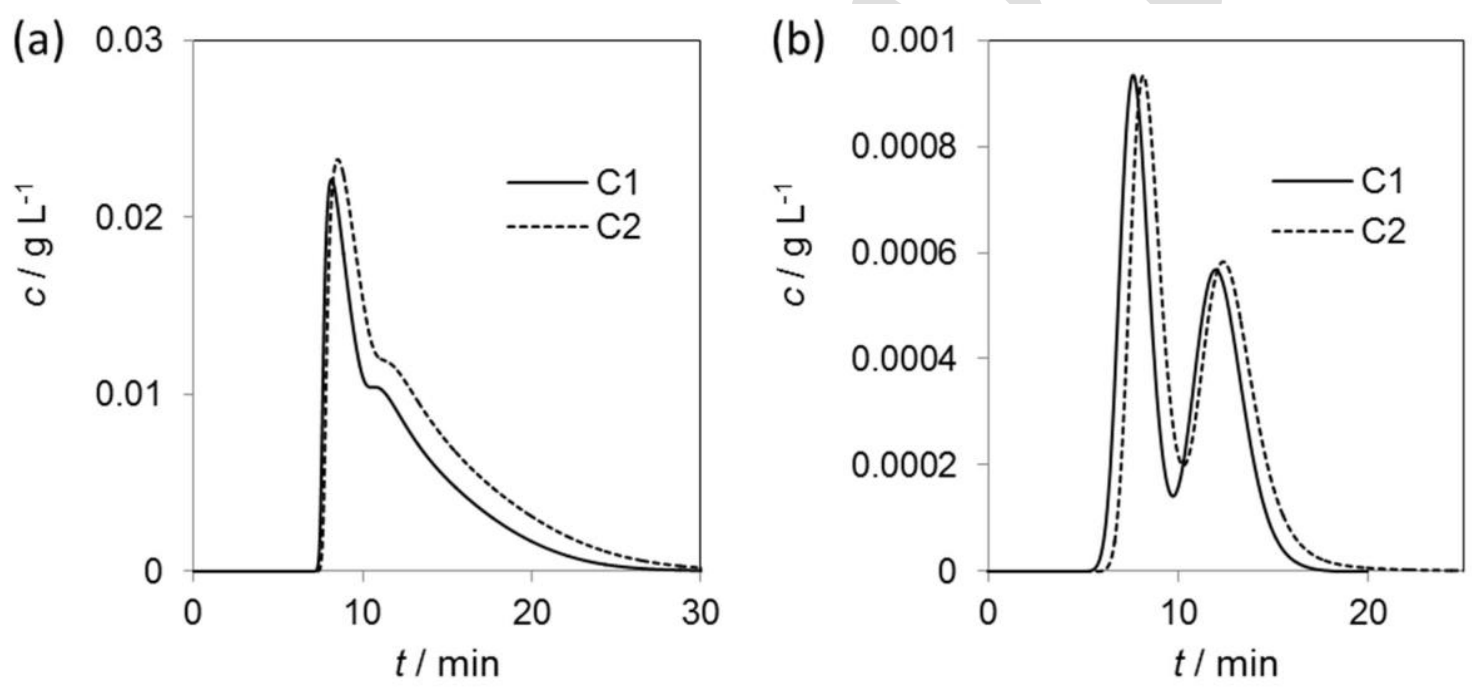

Figure 7. Experimental validation of the scale-up procedure illustrated by comparison of the experimental elution profiles for two columns: (a) Isoflurane $-C 1\left(d=0.6 \mathrm{~cm}\right.$, flowrate $71 \mathrm{~mL} \mathrm{~min}{ }^{-1}$, $\left.V_{i n j}=5 \mu \mathrm{L}\right)$ and C2 $\left(d=1.56 \mathrm{~cm}\right.$, flowrate $\left.492 \mathrm{~mL} \mathrm{~min}^{-1}, V_{i n j}=40 \mu \mathrm{L}\right)$; (b) Desflurane $-\mathrm{C} 1(d=0.6 \mathrm{~cm}$, flowrate $\left.21 \mathrm{~mL} \mathrm{~min}^{-1}, V_{i n j}=0.04 \mu \mathrm{L}\right)$ and $\mathrm{C} 2\left(d=1.56 \mathrm{~cm}\right.$, flowrate $\left.152 \mathrm{~mL} \mathrm{~min}^{-1}, V_{i n j}=0.4 \mu \mathrm{L}\right)$. 


\section{Tables}

Table 1. Experimental data for isoflurane and desflurane injections (for the small column $400 \times 6$ $\mathrm{mm})$.

\begin{tabular}{l|l|l}
\hline Total bed porosity $\varepsilon[-]$ & 0.81 & \multicolumn{2}{l}{} \\
Temperature $T\left[{ }^{\circ} \mathrm{C}\right]$ & 28 & Desflurane \\
\hline Substance & Isoflurane & 1465 \\
\hline Racemate concentration (liquid phase) $\left[\mathrm{g} \mathrm{L}^{-1}\right]$ & 1496 & 21 \\
Mobile phase flowrate $\dot{V}\left[\mathrm{~mL} \mathrm{~min}^{-1}\right]$ & 71 & 116.3 \\
Inlet pressure $P_{\text {in }}[\mathrm{kPa}]$ & 176.7 & 101.3 \\
Outlet pressure $P_{\text {out }}[\mathrm{kPa}]$ & 101.3 & $0.04,0.4,1$ \\
Injected volumes (liquid phase) $V_{\text {inj }}[\mu \mathrm{L}]$ & $0.04,0.4,1,2,3,4,5$ & $98 ; 85 ; 91$ \\
NTP (component 1; 2; mean) $[-]$ & $89 ; 80 ; 84$ &
\end{tabular}

Table 2. Competitive Langmuir adsorption isotherm (Eq. (4)) parameters $(H, b)$ and selectivity $(\alpha)$ of isoflurane and desflurane enantiomers at $28^{\circ} \mathrm{C}$.

\begin{tabular}{l|ll|ll}
\hline Parameters & Isoflurane & & Desflurane & \\
& $\mathrm{S}($ Component 1) & $\mathrm{R}$ (Component 2) & $\mathrm{S}$ (Component 1) & $\mathrm{R}$ (Component 2) \\
\hline$H[-]$ & 467.7 & 765.5 & 70.03 & 112.4 \\
$b\left[\mathrm{~L} \mathrm{~g}^{-1}\right]$ & 17.6 & 39.3 & 1.91 & 5.03 \\
$\alpha[-]$ & $1.64^{*}$ & & 1.61 & \\
\hline
\end{tabular}

* Compared to the values $1.30-1.34$ reported in [25] 
Table 3. Process performance characteristics of isoflurane and desflurane enantiomers for three typical cases.

\begin{tabular}{|c|c|c|c|c|c|c|}
\hline \multirow{2}{*}{$\begin{array}{l}\text { Case } \\
\text { Enantiomer }\end{array}$} & \multicolumn{2}{|c|}{ "Touching bands" } & \multicolumn{2}{|c|}{$\begin{array}{l}\text { Achieved maximal } \\
\text { productivity of S- } \\
\text { enantiomer }\end{array}$} & \multicolumn{2}{|c|}{$\begin{array}{l}\text { Achieved maximal } \\
\text { productivity of R- } \\
\text { enantiomer }\end{array}$} \\
\hline & $S$ & $\mathrm{R}$ & $S$ & $\mathrm{R}$ & $S$ & $\mathrm{R}$ \\
\hline & \multicolumn{6}{|c|}{ Isoflurane } \\
\hline$V_{i n j}[\mu \mathrm{L}]$ & \multirow{2}{*}{\multicolumn{2}{|c|}{$\begin{array}{l}0.0508 \\
0.0380\end{array}$}} & \multirow{2}{*}{\multicolumn{2}{|c|}{$\begin{array}{l}5.8 \\
4.34\end{array}$}} & \multicolumn{2}{|l|}{5.1} \\
\hline$m_{\text {feed }, 1}=m_{\text {feed }, 2}[\mathrm{mg}]$ & & & & & 3.81 & \\
\hline$P R\left[\mathrm{~g} \mathrm{~h}^{-1} \mathrm{~L}_{\text {ads }}^{-1}\right]$ & 0.0465 & 0.0465 & 3.29 & 2.82 & 3.2 & 2.85 \\
\hline$Y[-]$ & 0.989 & 0.988 & 0.644 & 0.551 & 0.704 & 0.625 \\
\hline$P \cup[-]$ & 0.993 & 0.992 & 0.991 & 0.991 & 0.991 & 0.991 \\
\hline \multicolumn{7}{|c|}{ Desflurane } \\
\hline$V_{i n j}[\mu \mathrm{L}]$ & \multirow{2}{*}{\multicolumn{2}{|c|}{$\begin{array}{l}0.0522 \\
0.0383\end{array}$}} & 6.80 & & \multicolumn{2}{|l|}{5.60} \\
\hline$m_{\text {feed }, 1}=m_{\text {feed }, 2}[\mathrm{mg}]$ & & & 4.98 & & 4.1 & \\
\hline$P R\left[\mathrm{~g} \mathrm{~h}^{-1} \mathrm{~L}_{\mathrm{ads}}^{-1}\right]$ & 0.126 & 0.127 & 7.06 & 6.02 & 6.87 & 6.06 \\
\hline$Y[-]$ & 0.982 & 0.976 & 0.595 & 0.507 & 0.693 & 0.612 \\
\hline$P U[-]$ & 0.992 & 0.990 & 0.992 & 0.991 & 0.992 & 0.990 \\
\hline
\end{tabular}

Table 4. Comparison of process performance parameters* of separating the enantiomers of isoflurane and desflurane. We took examples reported in the literature where the same chiral selector as in this work was used (two batch GC processes [23, 24] and one GC-SMB [25]).

\begin{tabular}{|c|c|c|c|c|c|c|c|}
\hline \multirow{2}{*}{$\begin{array}{l}\text { Parameter } \\
\text { Enantiomer }\end{array}$} & & \multicolumn{2}{|l|}{ Purity } & \multicolumn{2}{|c|}{$\begin{array}{l}\text { Productivity (Eq. (10)) } \\
{\left[\mathrm{g} \mathrm{h}^{-1} \mathrm{~L}_{\mathrm{ads}}^{-1}\right]}\end{array}$} & \multicolumn{2}{|c|}{ Recovery (Eq. (11)) } \\
\hline & & S & $\mathrm{R}$ & $S$ & $\mathrm{R}$ & $S$ & $\mathrm{R}$ \\
\hline \multirow{4}{*}{ Isoflurane } & [23] & 0.99 & 0.99 & 0.22 & 0.22 & $\sim 0.6$ & $\sim 0.6$ \\
\hline & [24] & 0.999 & 0.999 & 0.15 & 0.15 & \multirow{2}{*}{\multicolumn{2}{|c|}{$\begin{array}{l}\text { Not reported } \\
>0.95\end{array}$}} \\
\hline & [25] & 0.98 & 0.97 & 0.27 & 0.25 & & \\
\hline & This work & 0.99 & 0.99 & 3.29 & 2.82 & 0.64 & 0.55 \\
\hline \multirow{2}{*}{ Desflurane } & [24] & $\sim 0.91$ & $\sim 0.68$ & 1.94 & 1.75 & \multicolumn{2}{|c|}{ Not reported } \\
\hline & This work & 0.99 & 0.99 & 7.06 & 6.02 & 0.60 & 0.51 \\
\hline
\end{tabular}

* Partly the values of bed porosity $(\varepsilon)$ and the cycle time $\left(t_{c y c l e}\right)$ were not reported in $[23,24]$ and $[25]$, respectively. Then the following values were assumed for estimating the productivity: $\varepsilon=0.81, t_{\text {cycle }}=7 \cdot 24 \mathrm{~h}$, as used to evaluate our own results. 
Table 5. Scale-up results obtained based on the Eq. (12) by performing simulations. The operation and performance parameters are presented for two columns of different diameters and $400 \mathrm{~mm}$ length (named C1 and C2).

\begin{tabular}{|c|c|c|c|c|c|c|c|}
\hline \multirow{2}{*}{$\begin{array}{l}\text { Substance } \\
\text { Column }\end{array}$} & \multicolumn{4}{|c|}{ Isoflurane } & \multicolumn{3}{|l|}{ Desflurane } \\
\hline & \multicolumn{2}{|l|}{$\mathrm{C} 1$} & \multicolumn{2}{|l|}{$\mathrm{C} 2$} & $\mathrm{C} 1$ & \multicolumn{2}{|l|}{$\mathrm{C} 2$} \\
\hline$d[\mathrm{~cm}]$ & 0.6 & & 1.56 & & 0.6 & 1.56 & \\
\hline$\dot{V}\left[\mathrm{~mL} \mathrm{~min}^{-1}\right]$ & 71 & & 480.0 & & 21 & 142.0 & \\
\hline$V_{i n j}[\mu \mathrm{L}]$ & 5.8 & & 39.2 & & 6.80 & 46.0 & \\
\hline$t_{c y c l e}[\mathrm{~min}]$ & 23.8 & & 23.8 & & 11.7 & 11.7 & \\
\hline Enantiomer & $S$ & $R$ & $S$ & $R$ & $\begin{array}{ll}S & R\end{array}$ & $S$ & $\mathrm{R}$ \\
\hline$m_{i n j}[\mathrm{mg}]$ & 4.34 & 4.34 & 29.3 & 29.3 & $4.98 \quad 4.98$ & 33.7 & 33.7 \\
\hline$Y[-]$ & 0.64 & 0.55 & 0.64 & 0.55 & $0.60 \quad 0.51$ & 0.59 & 0.51 \\
\hline$P R\left[\mathrm{~g} \mathrm{~h}^{-1} \mathrm{~L}_{\mathrm{ads}}^{-1}\right]$ & 3.29 & 2.82 & 3.26 & 2.82 & 6.02 & 7.00 & 6.02 \\
\hline$m_{\text {coll/h }}\left[\mathrm{mg} \mathrm{h}^{-1}\right]$ & 7.07 & 6.05 & 47.3 & 40.9 & $15.2 \quad 12.9$ & 101.6 & 87.4 \\
\hline$t\left(m_{\text {coll }}=1 \mathrm{~g}\right)[\mathrm{h}]$ & 141.5 & 165.1 & 21.1 & 24.4 & $\begin{array}{ll}65.9 & 77.3\end{array}$ & 9.8 & 11.4 \\
\hline
\end{tabular}

Short text for the table of contents section

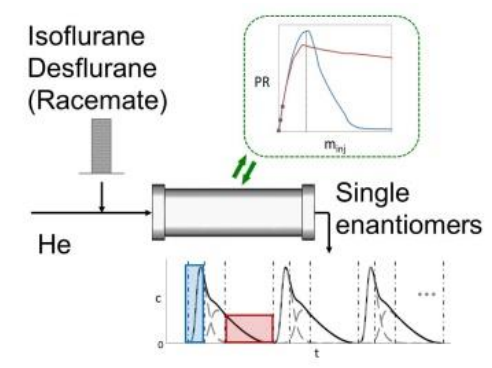

Separation of enantiomers of fluorinated anesthetic gases was investigated in gas-chromatographic columns employing a selector based on $y$-cyclodextrin. The batch process with repetitive injections was theoretically analysed to define the conditions that provide maximal productivity and high purity. The designed process can produce enough single enantiomers needed for further medical tests. 